\title{
ACADEMIA ESTUDANTIL DE LETRAS KIUSAM DE OLIVEIRA E A IMPORTÂNCIA DA REPRESENTATIVIDADE NA EDUCAÇÃO PARA AS RELAÇÕES ÉTNICO-RACIAIS
}

\section{‘ACADEMIA ESTUDANTIL DE LETRAS' AND THE IMPORTANCE OF REPRESENTATIVENESS IN EDUCATION FOR ETHNIC- RACIAL RELATIONS}

\author{
Samir Ahmad dos Santos Mustapha \\ Secretaria Municipal de Educação de São Paulo \\ Renata Takllan Rogow Leung \\ Universidade de São Paulo
}

\section{RESUMO:}

$\mathrm{O}$ artigo em tela procura trazer à tona e refletir sobre como o projeto Academia Estudantil de Letras (AEL), da Rede Municipal de Educação de São Paulo, constitui-se uma política pública sólida de promoção da leitura literária, e como pode, a partir disso, contribuir para a Educação das Relações Étnico-Raciais. O projeto AEL tem quinze anos de existência e, ao longo deste percurso, como preconiza Candido (2011), tem fomentado o direito à Literatura, bem como favorecido a inclusão, a autonomia dos alunos e melhoria da aprendizagem. A partir da experiência de uma das escolas que realiza o projeto, a AEL Kiusam de Oliveira, da EMEF Francisco Rebolo, na periferia da Zona Sul da capital paulista, pretendemos analisar a importância da representatividade negra no trabalho com práticas literárias bem como do acesso e fomento à Literatura como caminhos centrais no processo de Educação para as Relações Étnico-Raciais e formação crítica dos alunos.

Palavras-chave: Academia Estudantil de Letras, projeto educacional, literatura negra, políticas públicas afirmativas, representatividade.

\begin{abstract}
This article seeks to reflect on how the Academia Estudantil de Letras (AEL) project, of the Municipal Education Network of São Paulo, constitutes a solid public policy to promote literacy, and how it can, from
\end{abstract}


that, contribute to the Education for Ethnic-Racial Relations. The AEL project has been in existence for fifteen years and, along this journey, as also advocated by Candido (2011), it has fostered the right to Literature, as well as favoring inclusion, student autonomy and improved learning. Based on the experience of one of the schools that carries out the project, AEL Kiusam de Oliveira, from EMEF Francisco Rebolo, we intend to analyze the importance of black representation in the workplace with literary practices in addition to the access and promotion of Literature as a central path in the Education for Ethnic-Racial Relations process.

Key-words: Academia Estudantil de Letras, educationalproject, blackliterature, affirmativepublic policies, representativeness. 


\section{INTRODUÇÃO}

Projetos educacionais são importantes espaços pedagógicos para a experimentação, inovação, a criação de novas relações entre professor e estudantes, bem como amplia concepções curriculares, propiciando trazer à tona temáticas e elementos culturais pouco explorados e que intensificam o direito à educação como um bem público. O projeto Academia Estudantil de Letras (AEL) é uma exitosa experiência de formação cidadã pela literatura.

Criado pela professora Maria Sueli Fonseca Gonçalves - a Suelizinha- em 2005, a AEL começou na EMEF Padre Antonio Vieira, na Zona Leste de São Paulo, e foi se expandindo ao longo dos anos na região. A partir de 2015, a experiência foi oficializada com a Portaria 5.296/15, que promoveu a Academia Estudantil de Letras como um programa da rede municipal, começando assim a se expandir por toda a cidade: até então existiam 32 escolas participando do projeto. Com o processo de expansão e o aparato da Secretaria Municipal de Educação, o projeto AEL está presente atualmente em 165 unidades educacionais ${ }^{1}$.

Importante destacar que um ano antes da oficialização e expansão da AEL para toda a rede municipal, nasceu na mesma rede uma importante política pública, oficializada como "Projeto Leituraço"2. Baseado na Lei 10.639/o3-MEC3, o Leituraço foi lançado em outubro de 2014 e consistia inicialmente na "difusão, estímulo à leitura e estudo da produção literária africana e afro-brasileira" 4 .No ano de lançamento, as leituras e eventos se concentraram em duas semanas do mês de novembro, dada a expressividade

${ }^{1}$ Sobre o projeto AEL, ver a página oficial no Portal da Secretaria Municipal de Educação de São Paulo, no link: https://educacao.sme.prefeitura.sp.gov.br/ael/(Data do último acesso: 30/06/2020). A rede municipal de São Paulo é descentralizada em treze diretorias regionais, e os projetos AEL existem em todos os polos, tendo o trabalho de um coordenador em cada região e o órgão central, administrado pela Secretaria Municipal de Educação. A gestão e acompanhamento do trabalho e o desenvolvimento nas escolas é feita por esses profissionais.

${ }^{2}$ Sobre a política pública, ver Silva (2018).

3A Lei 10.639/o3 instituiu a obrigatoriedade do ensino de História da África e dos africanos no currículo escolar do ensino fundamental e médio.

4 https://www.prefeitura.sp.gov.br/cidade/secretarias/direitos humanos/igualdade racial/noticias/?p=1 84138(Data do último acesso: 30/06/2020) 
do mês em relação à cultura negra brasileira. Nos anos posteriores, contudo, o Leituraço também foi se expandindo, e a Secretaria Municipal de Educação de São Paulo (SME-SP) passou a dedicar uma verba anual para aquisição de literatura negra/ indígena/ imigrante/ periférica, além de promover formações docentes e semanas especiais ao longo de todo ano letivo para promoção da leitura e discussões relacionadas a essas temáticas.

Coincidência ou não, se as AELs formadas antes da expansão e do Leituraço tinham como patronos e patronesses apenas autores "consagrados" pela Academia - por exemplo, Machado de Assis, Clarice Lispector, Carlos Drummond de Andrade - conforme o projeto foi ganhando a cidade, acabaram surgindo Academias Estudantis com patronos e patronesses negros, indígenas, periféricos, demonstrando claramente a importância de políticas públicas afirmativas voltadas para a Educação das Relações Étnico-Raciais e para um trabalho literário que vá além dos ditos cânones literários.

Para trazer à tona a singularidade desta prática educacional, o presente artigo procura analisar como a escolha desses autores e autoras em projetos como a AEL representa um passo importante no processo de descolonizar o currículo, por meio do trabalho literário, e garantir, como preconizam as Diretrizes Curriculares Nacionais para a Educação das Relações Étnico-Raciais e para o Ensino de História e Cultura AfroBrasileira e Africana, o "igual direito às histórias e culturas que compõem a nação brasileira" (BRASIL, 2004, p.9). Antes dessa análise, porém, faremos uma breve consideração sobre a urgência de se reeducar as relações étnico-raciais no Brasil e de que forma a Literatura pode contribuir nesse processo.

\section{Por que reeducar as relações étnico-raciais no Brasil?}

Apesar do mito da democracia racial vigente no Brasil e da crença de que somos um país que acolhe a todos sem distinção, a última Pesquisa Nacional por Amostra de Domicílios (Pnad) Contínua do IBGE traz à tona, mais uma vez, o tamanho da 
desigualdade racial presente na sociedade brasileira 5. A pesquisa mostra que a desigualdade entre brancos e negros no Brasil se manifesta de diversas formas, desde índices de desemprego ou subemprego, ocupação de espaços de liderança no mercado de trabalho ou representação política, até índices de pessoas mais expostas à violência e homicídios ou da população carcerária no Brasil.

Para além de todos esses índices, contudo, ainda persistem na sociedade brasileira desigualdades raciais mais difíceis de serem mensuradas, como por exemplo, a persistência de um imaginário étnico-racial que privilegia a cultura, o conhecimento e o padrão estético branco europeu, enquanto ignora e/ou desvaloriza as culturas, conhecimentos e padrões estéticos indígenas e africanos. Tal imaginário permeia a sociedade brasileira, naturalizado muitas vezes não apenas na linguagem cotidiana, nas "brincadeiras" de mau gosto e apelidos, reforçando estereótipos discriminatórios construídos historicamente na sociedade, mas também na naturalização dos lugares sociais ocupados por negros e brancos - na maioria das vezes, os negros em posição servil em relação aos brancos -, como se a ocupação de tais lugares se desse por mérito, ignorando-se todo o processo histórico de exclusão e marginalização da população negra no Brasil após quatro séculos de escravidão.

Como apresenta Sodré (2015), espaços de grande difusão, como programas televisivos, propagandas comerciais, desenhos animados e obras literárias reforçam o discurso estereotipado sobre os negros e suas implicações na construção da identidade negra no Brasil.

A naturalização de tais desigualdades e injustiças raciais é tão forte no Brasil, que grande parte da sociedade se recusa a enxergar e ouvir os apelos e reivindicações daqueles que se engajam na luta antirracista, acusando-os de gerar vitimização e alegando que todas as pessoas merecem respeito, independente da cor da pele. Um exemplo foram os protestos desencadeados pelo assassinato brutal de George Floyd, um homem negro, por

5 Ver: "Dia da Consciência Negra: números expõe a desigualdade racial no Brasil". Em: https://piaui.folha.uol.com.br/lupa/2019/11/20/consciencia-negra-numeros-brasil/ (Data do último acesso: 07/07/2020)

@rquivo Brasileiro de Educação, Belo Horizonte, v. 8, n. 17, 2020 
um policial nos Estados Unidos. O assassinato de Floyd gerou protestos nas ruas e nas redes sociais. Mas assim que a hashtag "BlackLivesMatter" ou "VidasNegrasImportam" passou a ganhar relevância, surgiram pessoas levantando a hashtag "AllLivesMatter" ou “TodasasVidasImportam”, como se a luta antirracista fosse discriminatória, e não o racismo fortemente estruturado e arraigado nos EUA e no Brasil.

Além disso, práticas de extermínio da população negra também têm sido assustadoramente naturalizadas em um país onde, cotidianamente, jovens negros nas favelas são mortos pela violência e ações de milícias e polícia militar, reforçando a máxima na recente música de Seu Jorge, Marcelo Yuca e Wilson Capellette e já eternizada na voz da Elza Soares: “a carne mais barata no mercado é a carne negra”.

Tais embates expõem a maneira tensa como se dá a relação entre negros e brancos no Brasil: enquanto os primeiros lutam por respeito, igualdade de oportunidades e acesso aos diversos espaços sociais, os segundos, representados por uma elite do atraso (SOUZA, 2017), insistem em um negacionismo do racismo, perpetuando violências simbólicas cotidianas, enquanto levantam a bandeira da necessidade de "respeito a todos os seres viventes”. Esse negacionismo pode ter raiz no medo, já que o lugar da branquitude é um lugar de privilégio:

Se não é fácil ser descendente de seres humanos escravizados e forçados à condição de objetos utilitários ou a semoventes, também é difícil descobrir-se descendente de escravizadores, e temer, embora veladamente, revanche dos que, por cinco séculos, tem sido desprezados e massacrados. (BRASIL, 2014, p. 14).

A relação entre brancos e negros, contudo, não é tão simples e dicotômica assim: é preciso reconhecer que há pessoas brancas engajadas na luta antirracista, assim como há pessoas negras que negam a existência do racismo no Brasil e atacam o Movimento Negro, como o atual presidente da Fundação Palmares, Sérgio Camargo ${ }^{6}$. O processo de construção da identidade negra em nosso país é complexo e precisa ser analisado no

${ }^{6}$ Ver, por exemplo: https://g1.globo.com/politica/noticia/2020/06/02/sergio-camargo-presidente-dafundacao-palmares-chama-movimento-negro-de-escoria-maldita-em-reuniao.ghtml (Data do último acesso: 07/07/2020) 
contexto de uma ideologia do branqueamento que, desde a época da escravidão, divulga a ideia e o sentimento de que as pessoas brancas são superiores em inteligência e beleza até mesmo mais humanas! - e, portanto, tem todo o direito de estar em posições de comando e liderança na sociedade.

Nesse sentido, é possível que pessoas negras sejam influenciadas pela ideologia do branqueamento e, assim, tendam a reproduzir o preconceito do qual são vítimas. $\mathrm{O}$ racismo imprime marcas negativas na subjetividade dos negros $\mathrm{e}$ também na dos que os discriminam. (BRASIL, 2014, p.16)

Assim, reeducar as relações étnico-raciais no Brasil envolve combater a ideologia do branqueamento perpetrada por séculos em nossa sociedade, através da valorização do patrimônio histórico-cultural afro-brasileiro, bem como da estética negra, tão atacada e estereotipada a ponto de corroer a autoestima de crianças negras desde a mais tenra idade. Essa realidade social não apenas está presente no cotidiano escolar, como muitas vezes se apresenta às crianças, pela primeira vez, na escola, como relata a filósofa e escritora Djamila Ribeiro: "O início da vida escolar foi para mim o divisor de águas: por volta dos seis anos entendi que ser negra era um problema para a sociedade”(RIBEIRO,2019, p. 24). Diante disso, é urgente que se empreenda uma educação antirracista a fim de resistir e superar o imposto historicamente.

O mundo apresentado na escola era o dos brancos, no qual as culturas européias eram vistas como superiores, o ideal a ser seguido. Eu reparava que minhas colegas brancas não precisavam pensar o lugar social da branquitude, pois eram vistas como normais: a errada era eu. Crianças negras não podem ignorar as violências cotidianas, enquanto as brancas, ao enxergarem o mundo a partir de seus lugares sociais - que é um lugar de privilégio - acabam acreditando que esse é o único mundo possível. (RIBEIRO, 2019, p. 24)

Reeducar as relações étnico-raciais no Brasil implica também reconhecer que as relações entre brancos e negros são tensas, construídas num processo histórico de manutenção de privilégios de um lado, e marginalização e exclusão de outro; por isso, 
também são relações permeadas por medos, dores e culpas7. Por essa razão, a reeducação das relações étnico-raciais pede por um espaço de acolhimento, em que possa haver mútua valorização, trocas de saberes, de conhecimentos, "quebras de desconfianças, projeto conjunto para a construção de uma sociedade justa, igual, equânime" (BRASIL, 2014, p.14).

Claro que há muitos outros aspectos a serem estudados e refletidos na (re)educação para as relações étnico-raciais. Neste artigo, contudo, focaremos nos dois aspectos que mais se fazem presentes no cotidiano do projeto Academia Estudantil de Letras e que acreditamos contribuir grandemente nesse processo: (i) a valorização da estética negra e do patrimônio histórico-cultural afro-brasileiro através da Literatura; (ii) um espaço de acolhimento onde vínculos de confiança possam ser construídos, de modo que todas as crianças e adolescentes possam se sentir seguras para serem quem são e orgulhosos de seu pertencimento étnico-racial.

Na próxima sessão, faremos uma breve apresentação do que é o projeto AEL. Em seguida, mostraremos de forma mais detalhada como ele funciona e o impacto social que ele tem. Por fim, traremos um relato de experiência da AEL Kiusam de Oliveira, fundada em 2017, a fim de entender de que forma a Literatura pode contribuir para a Educação das Relações étnico-raciais, especialmente se trabalhada em projetos estruturados e com o amparo de políticas públicas afirmativas.

\section{O que são as Academias Estudantis de Letras}

$\mathrm{O}$ artigo em tela procura apresentar o projeto educacional denominado Academia Estudantil de Letras - AEL - como política pública da rede municipal de educação de São Paulo, tendo como proposta desenvolver o gosto literário nos alunos de forma lúdica,

\footnotetext{
7 É claro que os descendentes de escravizadores não têm culpa pelos atos de seus antepassados. Contudo, todos eles têm a responsabilidade moral de reconhecer as desigualdades da sociedade atual e, juntamente com os negros, lutar contra o racismo em todas as esferas possíveis de atuação.
} 
trabalhando os conceitos e os conteúdos em diálogo com outras formas de expressão culturais e artísticas.

A AEL é uma autêntica Academia de Letras com as devidas adaptações para o público estudantil. A iniciativa é desenvolvida nas Unidades Escolares da Rede Municipal de Ensino que se interessam em implantar o Projeto "Academia Estudantil de Letras AEL”, instituído pela Portaria 5.296/15, abrangendo do Ensino Fundamental ao Médio e a Educação de Jovens e Adultos, que integra práticas e culturas escolares já existentes na Rede Municipal de Ensino, promotoras do desenvolvimento integral dos estudantes, da equidade e da educação inclusiva.

As atividades do projeto se organizam em duas frentes: os encontros literários e as oficinas de teatro.

Dentro da dinâmica do projeto, são os próprios estudantes que escolhem um autor ou autora da literatura para representar na Academia. Uma das funções do professorcoordenador de Estudos Literários é repertoriar os alunos com uma ampla variedade de autores - de dentro ou fora do cânone. Então, cada aluno vai escolhendo os escritores e obras de que gostam e com quem se identificam, até optarem por um autor ou autora específico para representar na AEL e, assim, se tornar titular da cadeira literária, tomando posse, em solenidade organizada.

Ao escolher determinado escritor, o aluno - que passa a ser considerado um acadêmico - passa a receber orientação de pesquisa sobre a vida e obra do autor/autora, a fim de construir um percurso autônomo de aprendizagem. Quando se sente pronto, o aluno-acadêmico apresenta um Seminário Literário, compartilhando com os demais membros da Academia suas descobertas e textos preferidos.

Além dos momentos de orientação de leitura e estudos, os encontros literários buscam privilegiar os aspectos lúdicos presentes na leitura, através de variadas rodas de leitura e dinâmicas literárias, aproximando as crianças e adolescentes dos escritores. Se até um passado recente os escritores eram vistos como figuras muito formais e distantes dos leitores, os encontros literários buscam "humanizá-los", compartilhando aspectos cotidianos de suas histórias de vida, falando de sentimentos e, assim, buscando criar 
vínculos afetivos entre os autores e os jovens leitores da Academia Estudantil ${ }^{8}$. Esse vínculo com os autores é tão forte que, dentro do projeto, os autores escolhidos pelos acadêmicos passam a ser chamados de "amigos literários".

Já as atividades de teatro procuram trazer outras formas de expressão para os gêneros literários trabalhados, permitindo que os estudantes expressem a literatura de forma adaptada pelas artes visuais, dança, música e artes cênicas. Assim, se nos encontros literários, os estudantes têm espaço para sorver e compartilhar o que aprendem em suas leituras e pesquisas, nas oficinas de teatro, eles se familiarizam com a linguagem cênica a fim de poderem se expressar de forma artística, a partir dos conteúdos e vivências literárias.

Os encontros acontecem fora do horário regular das aulas, pois é optativo participar do projeto. Todas as ações se desenvolvem dentro de uma perspectiva que defende a expansão qualificada do tempo de permanência na escola, considerando as características, o contexto e o significado dessas ações para a vida dos estudantes. Os educandos que participam da AEL, em sua maioria, permanecem no projeto até a conclusão dos seus cursos e, muitos deles, mesmo depois de se formarem, continuam frequentando o projeto na qualidade de membros vitalícios da Academia.

Para abarcar o significado da proposta, utilizamos como pressuposto teórico estudos de Candido (2011), que define a literatura, em suas diferentes formas de expressão, como um direito inalienável do ser humano. O crítico afirma que a literatura humaniza porque nos faz vivenciar diferentes realidades e situações. A humanização, de acordo com Candido, é:

[...] o processo que confirma no homem aqueles traços que reputamos essenciais, como o exercício da reflexão, a aquisição do saber, a boa disposição para com o próximo, o afinamento das emoções, a capacidade de penetrar nos problemas da vida, o senso da beleza, a percepção da complexidade do mundo e dos seres, o cultivo do humor. A literatura desenvolve em nós a quota de humanidade na

${ }^{8}$ No caso de escritores ainda vivos, é possível ainda promover encontros pessoais ou virtuais entre os autores e os estudantes, como é o caso da AEL Kiusam de Oliveira. 
medida em que nos torna mais compreensivos e abertos à natureza, à sociedade e ao semelhante (p. 117).

Dentro dessa perspectiva de Candido (2011), reforçamos a importância da Literatura nas ações pedagógicas voltadas para a (re)Educação das relações Étnicoraciais: o poder da linguagem simbólica e literária permitindo a vivência de diferentes realidades e situações cria um ambiente propício de confiança e empatia, onde todos possam se sentir seguros e acolhidos em suas identidades pessoais e pertencimento étnico-racial.

Aliamos às ideias de Candido o pensamento de Freire (1989), que traz significado social ao ato de ler como um elemento fundante da formação do indivíduo. Freire afirma que viver precede a leitura: cada pessoa tem suas experiências individuais e, ao ler, muitos se identificam na forma escrita da leitura. Segundo o autor, "a leitura do mundo precede a leitura da palavra, daí que a posterior leitura desta não possa prescindir da continuidade da leitura daquele. Linguagem e realidade se prendem dinamicamente”. (FREIRE, 1989, p. 9).

Seguindo a linha de Freire (1989), no projeto AEL, as experiências individuais de cada estudante são valorizadas. Como descrito acima, após serem repertoriados com diversos autores - seja do cânone ou de fora dele - cada estudante tem autonomia para escolher seu próprio "amigo literário" e conduzir seu percurso de aprendizagem. $\mathrm{Na}$ maioria das vezes, é possível traçar um paralelo entre a escolha do amigo literário e a trajetória de vida de cada estudante. 9 Essa valorização da trajetória individual de cada um e de suas escolhas literárias tem se mostrado de grande valia tanto no processo de formação leitora, como na construção de um ambiente plural, ético e democrático.

Considerando o fato de que a escola pública é um ambiente constituído de múltiplos fatores e contextos sociais, além da vulnerabilidade social presente, o projeto se torna uma porta de entrada para inclusão e senso de pertencimento ao ambiente escolar. Petit (2008), a partir de sua experiência antropológica em pesquisas de formas de mediação e

\footnotetext{
9A análise da escolha dos amigos literários de cada estudante à luz de suas trajetórias de vida pode ser motivo para um estudo mais aprofundado.
} 
de construção do significado da leitura de sujeitos em diferentes circunstâncias sociais, defende que a democratização da leitura é um forte instrumento para o crescimento pessoal e profissional dos jovens.

\section{Impacto social do projeto AEL}

A partir do momento em que foi expandido de uma iniciativa regional para um programa em toda a rede municipal de ensino, o projeto tem ganhado contornos dentro da realidade social de cada escola na qual tem sido inserido, como ficará claro através da experiência da AEL Kiusam de Oliveira. Ao mesmo tempo, são 165 escolas a realizar o projeto, tendo uma unidade na sua realização.

Fruto de formações continuadas, acompanhamento técnico e descentralização da coordenação do projeto em ação contínua da Secretaria Municipal de Educação e Diretoria Regional de Educação, o trabalho pôde ser divulgado e replicado em diferentes espaços.

A política pública permitiu que a experiência não ficasse apenas na espontaneidade inicial, que claramente era singular, acolhedora e transformadora. A ação governamental permitiu dar suporte para que os professores fossem remunerados pelo trabalho diferencial que realizam, tivessem formação continuada para garantir sua aplicação qualitativa, e, além disso, que as escolas tivessem sua participação ativa na gestão do projeto AEL.

De forma organizada, o trabalho tem sido aplicado com unidade, garantindo que, de um ano para o outro, as ações não sejam interrompidas. Pelo contrário, o que se tem avaliado é que as escolas estão tendo a sua expansão na quantidade de turmas e professores envolvidos no projeto AEL.

Analisando a repercussão do projeto na Rede Municipal de Ensino de São Paulo é patente que o mesmo surgiu, pois havia a necessidade urgente de melhorar o quadro que se apresentava, de constatação de dificuldades de leitura entre os alunos dos primeiros anos do Ensino Fundamental II e, também, como uma tentativa de melhorar as relações no ambiente escolar, promovendo, o exercício de uma convivência pacífica, respeitosa e 
harmoniosa. A estratégia pedagógica escolhida foi, então, utilizar a Literatura, nessa perspectiva positiva, de mão dupla. Os primeiros resultados foram logos percebidos.

Em sala de aula, não tardou a ser notada a transformação dos alunos que se aventuravam a participar do projeto, por livre vontade, fora do horário de suas aulas. Eles iam se tornando, pouco a pouco, mais confiantes, a autoestima começava a ocupar um novo lugar e o interesse pela leitura aumentava sensivelmente.

O processo de construção e/ou resgate da autoestima é constante no projeto AEL. Além da valorização das escolhas e percurso de cada estudante individualmente, nas Oficinas de Teatro, os alunos interpretam textos, fazem adaptações de obras literárias para o palco e se preparam para solenidades como a Festa de Fundação da AEL, Festa Anual de Posse, Seminários internos e externos, Semana de Arte Moderna da AEL e apresentações culturais. Além disso, eventos como o "Chá Literário" e o "Seminário Mensal" são atividades pontuais, que contam com a presença da comunidade. Sempre que possível, a família dos acadêmicos é convidada para participar dos eventos promovidos pela AEL.

As "saídas culturais" são atividades realizadas no projeto, com a finalidade de oportunizar e favorecer o acesso incondicional à cultura, em sua diversidade, aos estudantes. A Semana de Arte Moderna da AEL é um evento anual de destaque, no qual os alunos têm a oportunidade de se apresentar nos palcos dos CEUs (Centros Educacionais Unificados) da Cidade de São Paulo, em uma semana consecutiva, manhã e tarde, alternando-se como plateia e protagonistas, vivenciando a literatura nas mais variadas linguagens: saraus, exposições de trabalhos, conversas com autores, apresentações cênicas de adaptações de obras literárias, espetáculos de dança e música, mostras de cinema e de arte, como exemplo.

O projeto AEL pode ser considerado inclusivo, pois todos os estudantes, sem nenhum critério de seleção, têm acesso ao Projeto AEL. A proposta valoriza a convivência, o acolhimento igualitário, a autoria e continuidade dos estudos, e o direito ao universo literário. 
Ao longo de seus 15 anos de existência, o projeto ganhou diversos prêmios, como: Prêmio "Professor-destaque" à professora idealizadora do projeto Academia Estudantil de Letras, no IV Congresso Municipal de Educação (2005);Prêmio Telefônica - Concurso "Causos do ECA" (2006); Menção honrosa da Fundação Nacional do Livro Infantil e Juvenil (FNLIJ) (2011); Certificação do Projeto como Tecnologia Social - BTS - Fundação Banco do Brasil (2013);Concurso Fundação Banco do Brasil - apresentação no Fórum Social Mundial da Tunísia (2013);Prêmio Fundação Banco do Brasil de Tecnologia Social (2015); entre outros. Além disso, diversas reportagens foram feitas sobre a singularidade do projeto e sua repercussão, levando o mesmo a ser reaplicado em diferentes redes de ensino.

O direito à literatura, apresentado pelos autores citados no artigo, verve o fazer literário de diferentes professores e alunos nas escolas espalhadas na periferia de São Paulo que realizam o projeto.

\title{
4. Relato de Experiência: AEL Kiusam de Oliveira - A Literatura e a Educação para as Relações Étnico- Raciais
}

\author{
“Ah, poetas Negros conhecidos e desconhecidos, com que \\ frequência suas dores loteadas nos seguraram? Quem \\ vai computar as noites solitárias amenizadas por suas \\ canções, ou as panelas vazias ressignificadas pelas suas
} histórias?" (Maya Angelou)

Como bem colocado por Djamila Ribeiro, é preciso falar sobre o racismo, por mais doloroso que seja. Afinal, é justamente "a falta de reflexão sobre o tema que constitui uma das bases para a perpetuação do sistema de discriminação racial. Por ser naturalizado, esse tipo de violência se torna comum" (RIBEIRO, 2019, p. 23). Falar sobre o racismo, especialmente entre crianças e adolescentes que ainda estão em processo de construção e formação de suas identidades, é algo que exige bastante sensibilidade, pois o assunto toca em feridas que costumam ser escondidas por parte de quem sofre. 
É aí que entra a importância e o poder da Literatura. Como bem expressa Maya Angelou em seu belíssimo relato autobiográfico "Eu sei por que o pássaro canta na gaiola", os poetas são aqueles que conseguem, através de suas canções e histórias, "amenizar as noites solitárias e ressignificar as panelas vazias”. Então, num rompante, ela expressa sua gratidão aos poetas negros, conhecidos e desconhecidos, como aqueles capazes de "nos segurar" nos momentos de dor.

Assim, o trabalho com a Literatura propicia não apenas reflexão intelectual, mas também acolhimento afetivo e emocional, lidando com as dores e o sofrimento de forma sensível. Mas o poder dos poetas não para por aí: além de acolher as dores, a Literatura abre portas, sugerindo outras realidades possíveis para além daquela imposta por uma sociedade desigual e, dessa forma, se torna um trampolim para transformações efetivas de realidades injustas e opressivas. Como salienta Ana Maria Gonçalves, umas das principais vozes de levante à literatura de forma democrática, sem discriminações raciais e estereótipos:

Eu encaro a literatura como o lugar das possibilidades. Numa folha de papel, ou qualquer outro meio, tudo é possível, inclusive adentrar em outros universos com os quais nunca tivemos ou teremos contato direto. Exercer a alteridade e repensar privilégios, oportunidades e inclusão, tanto de dentro quanto de fora do "sistema". Acho que essa capacidade de fazer pensar, sonhar, viver outras realidades é, não uma obrigação, mas uma das possibilidades mais interessantes da literatura. (FREDERICO, 2017, p. 251).

Como já descrito anteriormente, no Projeto AEL, cada estudante-acadêmico elege o autor de quem mais gosta ou com quem mais se identifica para ser seu "amigo literário". Mas, para além desses amigos de cada um, cada Academia tem um autor-patrono, eleito através de discussões do colegiado de professores e comunidade escolar. O patrono ou patronesse de cada Academia pode ser considerado o padrinho ou madrinha daquela escola; aquele cuja biografia e obra, cada membro da Academia, independente de seu amigo literário pessoal, deve conhecer. A autora eleita como patronesse da AEL da EMEF Francisco Rebolo foi Kiusam de Oliveira. 
A EMEF Francisco Rebolo está localizada no Distrito de Vila Andrade, zona sul de SP, onde a desigualdade social grita a olhos nus, tendo sido por diversas vezes capa de revista e fonte de diversas matérias jornalísticas. Esse Distrito abriga lado a lado os condomínios de luxo do Morumbi e as vielas de Paraisópolis, segunda maior favela de São Paulo. Conforme mapeamento caracterizado no Projeto Político-Pedagógico da escola, ela fica no alto de "um morro, bem íngreme, rodeado por terrenos baldios, árvores e áreas de muito barro" (Projeto Político-Pedagógico, 2020, p. 20) e atende a crianças e adolescentes de várias comunidades distintas, “porém todas vulneráveis e carentes da assistência governamental. São elas: Jardim São Roque, Jardim Ingá, Parque Arariba, Paraisópolis (estão aqui por falta de vaga na região), Parque Regina e Vila Andrade (Morro da Lua, Capadócia)” (Projeto Político-Pedagógico, 2020, p. 22).

A inserção em uma região extremamente desigual faz com que as questões raciais sejam bastante evidentes no cotidiano da escola. Reflexo de uma sociedade profundamente racista, ainda que a maioria dos alunos atendidos seja negra, quanto mais escuro for o tom da pele, maiores as chances de discriminação e sofrimento gerado por ofensas e piadas de mau gosto. Em depoimento aos autores, a professora Karina Ribeiro, que atua na Unidade Escolar há 10 anos, relata um episódio que a marcou enquanto docente e que, possivelmente, tenha influenciado a sugestão de Kiusam de Oliveira para ser patronesse da AEL local:

Sou professora da rede municipal de SP desde 2006. Na EMEF Francisco Rebolo, os temas relacionados à diversidade sempre permearam nossas discussões (de formação docente e com as práticas diárias com os alunos), porém nunca tivemos nenhum trabalho específico voltado ao tema étnico racial/ racismo. Mesmo assim, esse assunto sempre permeou minha prática.

Em 2014, peguei uma turma de $1^{\circ}$ ano que acompanhei até o $5^{\circ}$. (...) Quando eles estavam no $4^{\circ}$ ano, mudaram de turno, deixando de conviver apenas com alunos do fundamental I. Numa tarde, ao buscar a fila, deparei-me com uma aglomeração de alunos. A turma estava agitada e se posicionaram em volta de uma colega que chorava muito. Os alunos discutiam com uma jovem do $6^{\circ}$ ano. Eles diziam, com muita indignação, que o que ela tinha dito era racismo. Outros consolavam a colega que chorava.

Os alunos me relataram que a jovem do $6^{\circ}$ ano, havia chamado a colega que chorava de "macaca". Por isso a turma estava tão indignada, pois sabiam que 
esse termo é ofensivo e um ato de racismo. A turma precisou discutir o assunto durante mais de duas aulas, para o esgotarmos.

A maioria dos alunos se posicionou verbalmente contra o que a colega havia feito e repudiaram o racismo. A vítima sentiu-se acolhida e respeitada, a turma tomou uma atitude contra uma ação racista, sem violência/ agressão física $e$ verbal. E eu, a professora, fui orgulhosa e emocionada para casa.

A AEL Kiusam de Oliveira foi uma iniciativa muito importante para uma comunidade escolar, que precisava começar a discutir o racismo, algo tão recorrente para os moradores da periferia de São Paulo.

Foi a professora Karina quem sugeriu o nome de Kiusam de Oliveira para ser a patronesse da AEL da EMEF Francisco Rebolo. O processo de escolha de Kiusam foi interessante. A princípio, o colegiado estava votando os três autores mais indicados: Eva Furnari, Pedro Bandeira e Tatiana Belinky. Porém, o número de votos para cada autor foi muito parecido e, nas discussões, parecia impossível chegar a um consenso, já que os três autores mencionados são de indiscutível qualidade literária, além de uma obra extensa e reconhecida, ganhando facilmente os corações das crianças e adolescentes, bem como dos professores.

Diante do impasse, a professora Karina pediu licença para sugerir outra autora, naquela ocasião não tão conhecida na escola, mas de equivalente qualidade literária aos autores em discussão: Kiusam de Oliveira. A professora argumentou que além da qualidade literária de suas obras (muitas vencedoras de diferentes prêmios literários, inclusive), a vida e obra de Kiusam, militante do Movimento Negro Unificado desde os 13 anos de idade, tinham grande relevância social e poderiam ser de grande valia na forma como a escola precisava lidar com as questões raciais presentes em seu dia-a-dia: não mais de forma pontual ou isolada, seja nos conflitos instaurados ou nas discussões em sala de aula em datas especiais, mas de forma contínua e orgânica, através de um projeto que representaria toda a escola. Isso porque as ações realizadas até então, apesar de extremamente válidas, não pareciam suficientes para gerar transformação efetiva no combate ao racismo. É preciso um trabalho estruturado e contínuo, voltado especificamente para a luta antirracial, para "desnaturalizar o olhar condicionado pelo racismo" (Ribeiro,2019, p. 36). 
Não foi necessária outra votação: o colegiado aprovou unanimamente a sugestão da professora, e Kiusam de Oliveira foi eleita patronesse da Academia Estudantil de Letras da EMEF Francisco Rebolo. Quatro anos após o início das atividades, é possível ver que a professora Karina estava "redondamente certa". Kiusam de Oliveira é uma importante escritora negra a escrever para crianças no Brasil. Sua obra, mais do que denunciar o racismo impregnado em nossa história e na formação de nosso povo, tem um papel importantíssimo no processo de valorização da cultura, história e estética negra.

Ao longo de nossa história, é comum vermos pessoas negras reduzidas a uma "massa” esterotipada: "os negros", "os escravos", "neguinho isso, neguinho aquilo"10. Visto que nossa história desde muito tempo foi contada pelo ponto de vista do colonizador branco, os lugares de heroísmo e destaque - nas histórias ficcionais ou não-ficcionais costumavam ser, na maioria das vezes, atribuídos a personagens brancas, enquanto as personagens negras ficavam reduzidas a posições de subserviência ou diluídas em estereótipos convencionais, não sendo considerados, portanto, sujeitos da história.

Essa falta de representatividade negra no espaço escolar é uma das principais razões para a evasão ou o "fracasso" escolar por parte de estudantes negros. Oliveira (2008, p. 92) reúne diversas pesquisas onde se desnuda

a realidade brasileira, que é racista e sexista, levando crianças e jovens negros a abandonarem os bancos escolares por não se perceberem parte do todo e agentes capazes de transformar seus cotidianos pela Educação.

"Não há crime maior do que destituir um ser humano de sua própria humanidade" (RIBEIRO, 2019, p.26). Assim, é de suma importância que personagens negras sejam colocadas não só como protagonistas de suas próprias histórias, mas também em lugar de destaque e heroísmo na História do país, evidenciando as suas contribuições para a sociedade nas mais diversas áreas de atuação: nas artes, nas ciências, na política, enfim,

\footnotetext{
${ }^{10}$ Eisaqui um exemplo da força da linguagem no processo de desumanização da população negra no Brasil: a palavra "neguinho" costuma ser usada de forma genérica para referir a algo corriqueiro, geralmente algo ruim ou errado. Ninguém fala "branquinho" para se referir a ações corriqueiras da sociedade, porexemplo, ou como forma de diminuição da outra pessoa.
} 
no desenvolvimento da nação como um todo. Quantos escritores, intelectuais, engenheiros, cientistas, advogados negros foram apagados da História, ou embranquecidos nos retratos e ilustrações dos livros didáticos? Machado de Assis, André Rebouças, Luis Gama... a lista é longa. Além das muitas mulheres negras, das quais pouco (ou nunca) se ouve falar: Enedina Alves, Sonia Guimarães, entre tantas outras ${ }^{11}$.

Trazer protagonistas negros para as histórias - e da História - é algo que Kiusam de Oliveira faz com extrema maestria e sensibilidade. Pedagoga e conhecedora do universo infantil, Kiusam sabe do encantamento que a figura das princesas exerce sobre as meninas, por exemplo. Porém, quase não há princesas negras em nosso repertório cultural e literário, o que produz um efeito altamente negativo sobre a autoestimade meninas negras, já que seu ideal de beleza passa a ser referenciado pelo padrão branco, loiro e liso ${ }^{12}$. Kiusam de Oliveira, então, não apenas traz protagonistas negras para seus livros,mas as coloca em posição de realeza.

Assim faz Tayó: todas as manhãs ela se levanta da cama com a certeza de que é uma PRINCESA e, como de costume, projeta em seu penteado a mais exuberante COROA DE PALHA DA COSTA, BÚZIOS E OURO. [...] Tayó é o que todas as outras meninas como ela são: princesas que vivem a caaregar sobre seus penteados, suas COROAS REAIS, mesmo que não as vejam quando estão acordadas (OLIVEIRA, 2013, p. 36 -39).

O poder simbólico da coroa associada ao cabelo crespo e volumoso - vítima de tantos ataques e ofensas racistas, como "cabelo ruim", "bombril", entre outras comparações - é de uma importância difícil de ser mensurada e registrada em um artigo acadêmico. Mas quem já leu ou contou a história de Tayó para crianças negras pode confirmar o impacto desse simbolismo nos olhos brilhando e nos ouvidos atentos de crianças que vão, aos poucos, se reconhecendo na personagem: Tayó é uma menina de 6

\footnotetext{
${ }^{11} \mathrm{~A}$ esse apagamento sistemático de produções e saberes produzidos por grupos oprimidos, dá-se o nome de "epistemicídio" (Ver o capítulo "Leia autoresnegros", no "Pequeno Manual Antirracista”, de Djamila Ribeiro).

12 Além da forma como as princesas dos contos de fadas costumam ser representadas nos filmes e desenhos animados, podemos lembrar também das "Paquitas" e apresentadoras de auditório loiras que, por muitas décadas, formaram um imaginário infantil no qual o padrão de beleza estava posto.
} 
anos, amada por sua mãe, que sempre cuida muito bem dela e de seus cabelos. Ao chegar à escola, porém, se depara com a crueldade de colegas que, sem motivo, a ofendem, dizendo que seu cabelo é ruim. Apesar de toda mágoa e tristeza, embalada pelos Orixás, Tayó se ampara na "alma potente dos seus antepassados", lembrando-se de que é descendente da "mais nobre casta real africana" (OLIVEIRA, 2013, p. 31-32).

A história de Tayó traz dois grandes ingredientes da linguagem literária: a tristeza de Tayó pela ofensa que sofreu e pelas memórias das injustiças sofridas pelos seus antepassados acolhe e ampara a tristeza do jovem leitor/ouvinte da história, muitas vezes vítima das mesmas violências pelas quais Tayó passa. Então, quando o leitor/ouvinte está envolvido na história, identificado com a personagem, tendo suas emoções acolhidas, vem o ponto de virada, o lugar das possibilidades, o trampolim para a transformação: ao invés de se deixar abater pela tristeza, se sentindo diminuída e desvalorizada pelos xingamentos gratuitos dos colegas, Tayó é capaz de superá-la, apoiando-se nas memórias de seus ancestrais, fortes, nobres, REAIS.

Podemos nos perguntar por que a autora dá ênfase à palavra "real” junto de “coroa”. Afinal, toda coroa é associada à realeza. Não seria essa uma redundância desnecessária? Ora, essa é a beleza da linguagem literária: a palavra "real” carrega uma força semântica e um jogo de sentido que valem ser notados: se, por um lado, faz referência à imagem da realeza - reis e rainhas, príncipes e princesas - por outro, também remete ao sentido de "realidade". Assim, o cabelo crespo e volumoso que na maioria das vezes chega à escola preso, disciplinado ou alisado é comparado a uma coroa REAL: se a figura da princesa evoca o ambiente mágico dos contos de fadas, a ênfase no REAL reforça na mente e no coração do jovem leitor/ouvinte que a história de Tayó também é dele, é uma história REAL. Talvez seja por isso que a história de Tayó tenha forte apelo também entre crianças mais velhas e adolescentes, que já começam a perder o interesse por contos de fadas.

O empoderamento que Tayó traz a meninas e meninos negros pode ser visto nas palavras de Raiane, aluna de $7^{\circ}$ ano, integrante da primeira turma da AEL Kiusam de Oliveira, fundada em 2017. 
$O$ projeto AEL mudou muito minha vida, mudou minha autoestima completamente. Até hoje sou grata a Deus por eu ter tido a oportunidade de participar de um projeto tão especial, tão gratificante. Kiusam foi meu espelho, para eu poder seguir em frente, para eu dizer "eu vou conseguir". Uma mulher batalhadora, sofrida, mas mesmo assim tinha força para continuar, e eu fui aprendendo cada vez mais que eu tenho que ser do jeito que eu sou, não do jeito que eles querem que eu seja. Na vida, você tem altos e baixos, mas nunca pensar em desistir! Quem nasce Tayó é sempre Tayó!(Raiane Ribeiro de Oliveira, 16 anos).

Em um encontro literário onde foi lido "O mundo no Black Power de Tayó" e apresentada a biografia de Kiusam de Oliveira com relatos de racismo que a autora sofreu na infância, Raiane começou a chorar. Após a insistência do grupo, ela começou a contar o quanto sofria por causa dos apelidos e brincadeiras de mau gosto que ouvia todos os dias na escola e, especialmente, no caminho para casa. Contou também do quanto se sentia feia e não gostava de quem era. Todos ficaram surpresos, pois Raiane costumava ser uma menina sempre alegre e risonha e, por isso, os colegas achavam que ela não se importava com as ofensas. Tal relato de alguém tão próximo comoveu os demais colegas, que choraram junto com ela e pediram desculpas - alguns por terem tido parte ativa nas ofensas, outros por terem sempre se omitido diante das violências que a amiga sofria.

Como já foi descrito anteriormente, o projeto AEL conta com as frentes literária e de teatro. Assim, naquele mesmo ano - 2017 - a turma decidiu que deveria adaptar o texto de "O mundo no Black Power de Tayó" para os palcos. Ao contrário do que costuma acontecer em peças escolares, não houve brigas nem disputas para o papel principal: todos sabiam que o papel pertencia à Raiane, que interpretou Tayó como uma atriz profissional, incorporando ao mesmo tempo as dores e a potência da personagem.

Assim como não houve disputas para o papel principal, também não houve disputas para os demais papeis. Parece que os alunos haviam entendido a importância de cada personagem na formação da história/História: a mãe de Tayó, os povos sequestrados e escravizados, os Orixás que embalam o sono de Tayó.

A peça foi apresentada diversas vezes: estreou no palco da Academia Paulista de Letras, por ocasião da abertura da Semana de Arte Moderna (já descrita anteriormente), 
e seguiu sendo apresentada no palco de diferentes CEUs da cidade, bem como na própria escola, sendo motivo de grande alegria e orgulho para os participantes, bem como de inspiração e reflexão para os que a assistiam. Segundo a professora de português Pâmella Cabral, a apresentação da peça de Tayó e as demais apresentações da AEL ao longo do ano (como o Chá Literário, por exemplo) foram eventos importantes que impulsionaram a leitura e o estudo de autores negros, bem como o debate sobre racismo, também nas salas de aula.

Além disso, a escolha de Kiusam de Oliveira como patronesse da AEL, as leituras de suas obras, as rodas de conversa e as pesquisas sobre sua biografia inspiraram o interesse dos alunos por outras autoras negras. Assim, começaram a sair das prateleiras os livros de Carolina Maria de Jesus e Conceição Evaristo, que se tornaram as cadeiras de número 2 e 3, respectivamente (a cadeira número 1 sendo obviamente de Kiusam de Oliveira). Esse foi um ponto de partida que tem alimentado o interesse e a curiosidade por outros autores e autoras negros, bem como por literatura africana e indígena, fortalecendo cada vez mais no ambiente escolar o reconhecimento e a valorização de todas as etnias.

\begin{abstract}
A importância de estudar autores negros não se baseia numa visão essencialista, ou seja, na crença de que devem ser lidos apenas por serem negros. A questão é que é irrealista que numa sociedade como a nossa, de maioria negra, somente um grupo domine a formulação do saber. É possível acreditar que pessoas negras não elaborem o mundo? (...) O privilégio social resulta no privilégio epistêmico, que deve ser confrontado para que a história não seja contada apenas pelo ponto de vista do poder. É danoso que, numa sociedade, as pessoas não conheçam a história dos povos que a construíram (RIBEIRO, 2019,p. 64-65)
\end{abstract}

O poder de Tayó e a importância de um trabalho estruturado com a literatura negra ficam evidentes não apenas no impacto sobre a autoestima e no processo de empoderamento de meninas e meninos negros em idade escolar, mas também na transformação de sua relação com os livros e com o espaço-instituição "escola". No caso da AEL Kiusam de Oliveira, foi muito nítida a mudança no interesse e na relação que os 
alunos começaram a desenvolver com os livros e os estudos a partir do momento em que começaram a se ver representados e referenciados positivamente nas histórias.

Assim, se formos falar dos impactos de projetos estruturados e voltados para uma Educação antirracista, vemos que, se antes contabilizávamos índices de evasão escolar da população negra, podemos começar a perceber um processo de apropriação tanto desse espaço, quanto do processo de construção do conhecimento. Mesmo diante das particularidades locais de cada escola, uma vez que ela é um microcosmo dos outros espaços sociais, tal processo é fundamental para a construção de uma sociedade verdadeiramente democrática e igualitária. Como afirma Oliveira (2008, p. 89) em sua pesquisa de Doutorado, “o campo da Educação tem se constituído em terreno fértil para a reflexão combativa das desigualdades na sociedade brasileira e nas relações de poder que se estabelecem neste espaço".

Tais impactos, contudo, só são possíveis se o pensar sobre a educação das relações étnico-raciais estiver presente no dia-a-dia da escola. Uma vez que o racismo está internalizado em cada um de nós - "é impossível não ser racista tendo sido criado em uma sociedade racista”, afirma Djamila Ribeiro (2019, p.38) - não será possível combatê-lo apenas com atividades pontuais em datas específicas.

Eleger uma patronesse negra para um projeto como a AEL foi de uma força simbólica que não se imaginou a princípio. Como atesta a professora de português Pâmella Cabral, atuante na EMEF Francisco Rebolo há nove anos, o fato de a patronesse ser negra e o estudo de sua história fortaleceram os diálogos sobre racismo na escola:

Impactados pela peça do "Mundo no Black Power de Tayó", que foi incrível para abordagem do racismo e com foco muito importante na questão do cabelo como potência e ancestralidade afro, como também para falar sobre os padrões de beleza e o projeto de embranquecimento do Brasil, as leituras das obras da autora com protagonistas negras e tratando da temática racial não ficaram restritas à AEL, mas expandiram-se pela escola como um todo. Aos poucos, as questões raciais presentes no dia-a-dia da escola, como xingamentos e ofensas, começaram a ser trazidas pelos alunos para serem discutidas nas assembléias de sala de aula e mediadas pela Comissão Mediadora de Conflitos. O racismo também começou a aparecer como tema de estudo escolhido pelos alunos para produção de artigos de opinião. Enfim, Com uma AEL atuante como a nossa, este trabalho possibilita outros tantos que partem de uma vivência dos alunos 
com a leitura. As temáticas estão presentes e fazem parte do dia-a-dia na escola e não apenas nas datas comemorativas. (Pâmella Brum Pereira Cabral, professora de português da EMEF Francisco Rebolo).

Por fim, qualquer projeto de combate ao racismo precisa discutir o lugar e o papel das pessoas brancas/não-negras nessa luta, não no sentido de culpá-los, mas no sentido de lhes lembrar de uma realidade que, apesar de gritante, não vivem e, por isso, muitas vezes não se importam. Como afirma Djamila Ribeiro,

a posição social do privilégio vem marcada pela violência, mesmo que determinado sujeito não seja deliberadamente violento. (...) ter consciência da prevalência branca nos espaços de poder permite que as pessoas se responsabilizem e tomem atitudes para combater e transformar o perverso sistema racial que estrutura a sociedade brasileira. (RIBEIRO, 2019, p. 33).

A discussão sobre racismo versus o lugar de privilégio da branquitude muitas vezes acaba reduzida a trocas de acusações, justificativas baratas ou argumentos rasos e universalistas (como aquele de que "todos merecem respeito"), como as redes e fóruns sociais tem evidenciado nos últimos anos. O trabalho desenvolvido na AEL Kiusam de Oliveira revelou que a Literatura é um excelente lugar para discutir questões como essas. Afinal, sendo um lugar de sensibilidade, a Literatura, mais do que argumentos racionais ou históricos, tem o poder de despertar a empatia e alteridade, como fica evidente no depoimento de Ester:

Não fazia a mínima ideia do que o racismo realmente provocava, até começar a ter os encontros da AEL e ouvir situações de pessoas próximas que sofriam preconceito por causa da sua cor, o que me trouxe uma visão mais ampla do que realmente o racismo provocava à minha volta. Por exemplo, uma vez, quando estávamos reunidas num encontro literário do projeto falando sobre racismo, uma amiga próxima minha começou a falar sobre coisas que ela passava na escola que a deixavam bastante magoada. Ela contou de como falavam da cor da pele dela e também do cabelo, o que me comoveu bastante. Confesso que nunca passei por problemas assim, mas depois que percebi o que acontecia ao meu redor, comecei a me colocar no lugar das pessoas que passavam por isso, $o$ que me estimulou a conhecer mais sobre a História e me aprofundar mais sobre esses assuntos. (Ester Carvalho, 16 anos, integrante da AEL Kiusam de Oliveira).

De fato, um dos pilares da AELé a cultura de paz. O projeto prima pela convivência, e a literatura e as artes consolidam os pilares da paz no trabalho coletivo, acolhedor, no 
qual todos os interessados podem participar. A valorização da diversidade, a inclusão, a alteridade são tecidos nos encontros, no ambiente fraterno. Não por acaso os alunos, em geral, chamam o ambiente de "família AEL".

No projeto, cada estudante tem a oportunidade de ter um lugar de destaque, uma “cadeira”, construída a partir de seus gostos e preferências pessoais, sua individualidade. Assim, mais do que inclusão, investe na valorização de cada um, com seus limites e potenciais. Claro que esse processo de valorização das individualidades é importante em qualquer AEL - em qualquer projeto educacional como um todo! - mas naquelas cujos patronos são negros, tal processo não é apenas importante: é revolucionário.

\section{CONCLUSÃO}

A experiência do projeto Academia Estudantil de Letras Kiusam de Oliveira, além de outras AELs com patronos e patronesses negros espalhadas pela cidade de São Paulo, demonstra o quanto a representatividade negra na Literatura é um caminho efetivo de luta contra o racismo no processo de Educação para as relações étnico-raciais. Afinal, em um país onde sempre imperou o esforço por marginalizar, desvalorizar e rebaixar a população negra em todos os aspectos constituintes de suas identidades - constituição física, matrizes religiosas, valores, cultura, contribuição social, acadêmica e econômica na construção da nação -, é urgente que se façam esforços dobrados para resgatar as histórias que foram apagadas, escondidas e ignoradas, juntamente com a autoestima e orgulho de seu pertencimento étnico-racial que, muitas vezes, ficaram pelo caminho.

São muitos os impactos da emergência de autores e protagonistas negros no cenário literário, bem como de projetos educacionais que viabilizam o acesso dos estudantes a tais obras. A partir da experiência da AEL Kiusam de Oliveira, podemos citar, por exemplo: (i) a melhora da autoestima e o empoderamento de meninos e meninas negros; (ii) o combate à ideologia do branqueamento em um espaço de sensibilização, escuta afetiva e acolhimento, refletindo também sobre o papel dos brancos/não negros na luta contra o racismo; (iii) a transformação na relação de crianças e jovens negros com os livros e a 
escola, facilitando, dessa forma, a sua apropriação de um espaço que, por séculos, lhes foi negado.

De fato, o projeto Academia Estudantil de Letras estrutura-se sobre dois pilares que, somados ao impacto e importância de uma patronesse negra, parecem contribuir fortemente para o processo de educação das relações étnico-raciais no Brasil: (i) o espaço de valorização e destaque de cada aluno, individualmente; (ii) a cultura de paz, trabalhada em um espaço de acolhimento e escuta afetiva.

Ao contrário do que parece estar inculcado na mente daqueles que resistem à luta antirracista, a valorização e o resgate das narrativas negras, bem como de toda sua contribuição histórica e social, não representa qualquer ameaça aos brancos/não-negros. Muito pelo contrário: a construção de uma nação verdadeiramente democrática e igualitária, com índices sólidos de desenvolvimento econômico e social, passa necessariamente pelo combate e fim do racismo, especialmente em um país em que a população negra é fundante e formadora do próprio povo. Enquanto não nos dermos conta disso, como sociedade, continuaremos sufocados por uma lógica de opressão, em que o progresso de alguns poucos se alimenta da exploração de muitos.

Por fim, a experiência de projetos como a AEL e o Leituraço reforçam a urgência de políticas públicas, bem como de ações contínuas e estruturadas no processo de Educação étnico-racial, pois se o racismo está embrenhado e institucionalizado em nossa sociedade, só seremos capazes de combatê-lo embrenhando e institucionalizando iniciativas antirracistas em nossas rotinas.

\section{Referências:}

ANGELOU, Maya. Eu sei por que o pássaro canta na gaiola. Bauru, SP: Astral Cultural, 2018.

BRASIL. Ministério da Educação/Secad. Diretrizes curriculares nacionais para a educação das relações étnico-raciais e para o ensino de história e cultura afro-brasileirae africana na educação básica. 2004. 
CABRAL, Pâmella Brum Pereira. Depoimento da professora sobre a AEL.

Entrevista concedida a Renata Takllan Rogow Leung em 2020.

CANDIDO, Antonio. O direito à literatura. In: CANDIDO, Antonio. Vários escritos. Rio de Janeiro: Ouro sobre o azul, 2011.

CARVALHO, Ester. Depoimento da aluna sobre a AEL. Entrevista concedida a Renata Takllan Rogow Leung em 2020.

FREIRE, Paulo. A importância do ato de ler: em três artigos que se completam. São Paulo: Autores Associados; Cortez, 1989.

FREDERICO, Graziele; MOLLO, Lúcia Tormin; DUTRA, Paula Queiroz. “A literatura é o lugar das possibilidades": entrevista com Ana Maria Gonçalves. Estud. Lit. Bras.

Contemp. [online]. 2017, n.51, pp.249-253.

OLIVEIRA, Kiusam Regina de. Candomblé de Ketu e Educação: Estratégias para o empoderamento da mulher negra. Tese de Doutorado: Universidade de São Paulo, 2008.

O mundo no Black Power de Tayó. São Paulo: Peirópolis, 2013.

OLIVEIRA, Raiane Ribeiro. Depoimento da aluna sobre a AEL. Entrevista concedida aRenata TakllanRogow Leung em 2020.

PROJETO POLÍTICO-PEDAGógICO. EMEF Francisco Rebolo. 2020.

PETIT, Michele. Os jovens e a leitura. São Paulo, Editora 34, 2008.

RIBEIRO, Djamila. Pequeno Manual Antirracista. São Paulo: Cia das Letras, 2019.

RIBEIRO, Karina. Depoimento da professora sobre a AEL. Entrevista concedida a Renata TakllanRogow Leung em 2020.

SILVA, Luciene Ribeiro da. O Projeto Leituraço: significados para a descolonização do currículo. Dissertação de mestrado em Educação: Currículo. Pontifícia Universidade Católica de São Paulo, 2018

SODRÉ, Muniz. Claros e escuros: Identidade, povo, mídia e cotas no Brasil. 3. Ed. Petrópolis: Vozes, 2015.

SOUZA, Jessé. A elite do atraso: da escravidão à Lava-jato. São Paulo: Leya, 2017. 


\section{Sobre os autores:}

Samir Ahmad dos Santos Mustapha: Doutor pelo programa Educação: História, Política, Sociedade na Pontifícia Universidade Católica- SP (2019), na linha de pesquisa: Educação Brasileira: Produção, Circulação e Apropriação Cultural. Participa como pesquisador no Grupo de Pesquisa: História das Instituições e dos Intelectuais da Educação Brasileira e do projeto de pesquisa coletivo: História das Instituições Educacionais: intelectuais, políticas e práticas. Atualmentetrabalha no Núcleo Técnico de Currículo, da Coordenadoria Pedagógica da Secretaria Municipal de Educação de São Paulo (SME). E-mail: mustapha.samir@hotmail.com

Renata Takllan Rogow Leung: Mestre em Linguística e Semiótica Geral pela Universidade de São Paulo e Especialista em Educação, Ética e Cidadania na Escola pela Univesp (Universidade Virtual do Estado de São Paulo/USP). Atuou como professora de Língua Portuguesa em escolas da rede pública e privada de SP e, em 2015, assumiu o cargo de Professora Orientadora de Sala de Leitura da EMEF Francisco Rebolo (Rede Municipal de SP), onde coordenou diversos projetos como a Academia Estudantil de Letras Kiusam de Oliveira e o projeto Yoga na Escola. Atualmente, estuda língua e cultura holandesas na Fundação Intercultural para Mulheres (SIVE), em Enschede/Holanda. E-mail: renataleung@gmail.com 